\title{
MICHELIN TIRE BABY SYNDROME VARIANT
}

A syndrome of multiple congenital anomalies, mental retardation, and symmetrical circumferential skin creases of arms and legs in a 4.5-year-old male is reported from the Montreal Children's Hospital, Quebec, Canada. Craniofacial anomalies included a high forehead, microphthalmia, optic nerve hypoplasia, telecanthus, and micrognathia. CT showed dilated lateral ventricles. Chromosomes were normal. (Elliott AM, Ludman M, Teebi AS. New syndrome?: MCA/MR syndrome with multiple circumferential skin creases. Am I Med Genet 1996;62:23-25). (Reprints: Dr AS Teebi, Division of Medical Genetics, Montreal Children's Hospital, 2300 Tupper Street, Montreal, Quebec, Canada H3H 1P3).

COMMENT. This mental retardation syndrome resembles the "Michelin tire baby syndrome" but has some additional unique anomalies.

\section{NONSPECIFIC BRAIN ANOMALIES IN AUTISM}

Measurements of the cerebellar vermis in 125 normal individuals and 102 patients with a variety of neurogenetic abnormalities were compared, using quantitative MRI analysis in a study at the Universities of Nebraska, Omaha; Oklahoma, Norman; West Virginia, Morgantown; and Texas, San Antonio. The average size of cerebellar vermal lobules (CBL) VI and VII in patients with infantile autism was not significantly different from that in agematched normal subjects. Relative CBL VI-VII hypoplasia occurred in patients with Rett syndrome and Sotos' syndrome, both having autistic behaviors, but the same was true for conditions without autistic behaviors. CBL VI-VII hypoplasia is not limited to disorders with autistic behavior and is not a specific neuroanatomical marker for autism. (Schaefer GB, Thompson JN Jr, Bodensteiner JB et al. Hypoplasia of the cerebellar vermis in neurogenetic syndromes. Ann Neurol March 1996;39:382-385). (Respond: Dr Schaefer, University of Nebraska Medical Center and Meyer Rehabilitation Institute, 600 S 42nd Street, Omaha, NE 68198).

COMMENT. Several neurogenetic disorders have relative CBL VI-VII hypoplasia, and cerebellar vermal hypoplasia is not specific for autism.

Temporal lobe morphology in childhood-onset schizophrenia was studied by MRI in 21 patients examined at the NIMH, the University of Maryland School of Medicine, Baltimore, and Northwestern University School of Medicine, Chicago. (Jacobsen LK et al. Am I Psychiatry March 1996;153:355361). These schizophrenic patients had smaller cerebral volumes, but larger volume of the superior temporal gyrus. They lacked the normal (rightgreater-than-left) hippocampal asymmetry. Early onset schizophrenia was not associated with a severe medial temporal lobe lesion in these patients.

\section{LEARNING AND BEHAVIOR DISORDERS}

\section{CLONIDINE FOR SLEEP DISORDERS WITH ADHD}

A retrospective analysis of 62 children and adolescents treated with clonidine for sleep disturbances associated with ADHD is reported from the outpatient Pediatric Psychopharmacology unit, Massachusetts General Hospital, Boston. Using the National Institute of Mental Health global assessment of sleep improvement, $85 \%$ of patients treated with nighttime clonidine (50-800 mcg, mean 157) for 35 months were much to very much improved. Concurrent pharmacotherapy and comorbidity showed no relation 